\title{
Modelling of Cracked Concrete and Identification of Design Parameters Using Static Non-linear Analysis
}

\author{
Shifana Fatima Kaafil Rehumaan \\ Hekma School of Design and Architecture, Dar Al-Hekma University, Jeddah, Kingdom of Saudi Arabia
}

Received July 15, 2021; Revised December 30, 2021; Accepted January 16, 2022

\section{Cite This Paper in the following Citation Styles}

(a): [1] Shifana Fatima Kaafil Rehumaan, "Modelling of Cracked Concrete and Identification of Design Parameters Using Static Non-linear Analysis," Civil Engineering and Architecture, Vol. 10, No. 2, pp. 584-599, 2022. DOI: 10.13189/cea.2022.100216.

(b): Shifana Fatima Kaafil Rehumaan (2022). Modelling of Cracked Concrete and Identification of Design Parameters Using Static Non-linear Analysis. Civil Engineering and Architecture, 10(2), 584-599. DOI: 10.13189/cea.2022.100216.

Copyright $(2022$ by authors, all rights reserved. Authors agree that this article remains permanently open access under the terms of the Creative Commons Attribution License 4.0 International License

\begin{abstract}
Disaster mitigation in developing countries calls for use of locally available composite materials and technology for faster implementation. The behavior of concrete with composites at vulnerable locations is considerably improved in non-linear form. The focus of the study is to provide design inputs for rehabilitation of damaged beam using locally available composite materials based on nonlinear static analysis. The study models are the tensile zone of a beam structure using finite elements and pre-assigned crack widths and crack depth. By non-linear material analysis, the stiffness variation is found out, approximated in a bilinear form then given as an input to get stiffness and displacement of the models before and after modulus of rupture for concrete. The model developed in this paper involves a lot of uncertainties and thereby fuzzy logic has been used to handle these uncertainties. The percentage increase in stiffness and percentage reduction in displacement for undamaged, damaged concrete model and concrete rehabilitated with composite are found using fuzzy logic then compared with the results obtained from finite elements analysis. The method developed in this paper is validated with an example, showing the percentage increase via load carrying capacity of the beam and the different types of repairs and rehabilitation. The equations developed in this paper are recommended for design implementation of cracked, uncracked and damaged specimens using locally made different composites.
\end{abstract}

Keywords Modelling, Crack Width, Bilinear Form, Rehabilitation and Damaged Beam

\section{Introduction}

Materials like concrete exhibit considerable non homogeneity and nonlinearity both in cracking and response even under normal load conditions. This gets pronounced if the structures have cracked or subjected to damage. Composites and equivalent SDOF models are used adequately to get the response and later to give the design guidelines. But most of these are for uncracked sections only and hence there is a need to reflect cracking and to develop a design procedure which will reflect true behavior. Normally, it is difficult to suggest a composite for repair of damaged and cracked beam. In this paper, an attempt has been made to study the stiffness and displacement of different models and design suggestions are given for rehabilitation of cracked and damaged beam under static loading by the application of composite materials. For rehabilitation, any type of composite material can be used, provided the ratio of modulus of elasticity of the chosen composite materials to modulus of elasticity of concrete (of grade 30) is greater than 1 .

\section{Cracking in Beams}

Cracking in plain concrete and reinforced concrete beams can be done in two ways: first by using Fracture Mechanics (FM) and next by reducing Material Property (Young's modulus E). For plain concrete, the crack will progress up to centre whereas for reinforced concrete it will stop at reinforcement level. So crack length is not limited in plain concrete beams. In this method, deflection and 
stress increase, at the tip of the crack for different crack widths. Some typical fracture parameters are Stress intensity factors $\left(\mathrm{k}_{1}, \mathrm{k}_{11}\right.$ and $\left.\mathrm{k}_{111}\right)$ associated with the basic modes of fracture and energy release rate $(\mathrm{G})$, which represents the amount of work associated with a crack opening or closure [1].

\section{Mechanism of Concrete Fracture}

Analysis of concrete is essential in developing an analytical model to predict material response and consideration of the physical mechanism of behavior may facilitate the development process and simplify the model formulation [2]. Non-destructive testing has developed in recent years and now in-situ monitoring can be used during testing in order to determine crack location, crack length, crack propagation modes, crack path and shape [3-4].

The two main mechanisms of damage in concrete under loading are:

(1) De-bonding at the interface between aggregate and cement paste.

(2) Micro cracking in the matrix.

Various models based on nonlinear fracture mechanics that describe the fracture process zone in plain concrete (unreinforced) and reinforced concrete have been developed, such as

(1) Fictitious Crack Model (FCM) proposed by Hillerborg [5].

(2) Crack Band Model (CBM) proposed by Bazant and Planas [6].

(3) Two Parameter Model (TPM) based on effective crack length was proposed by Jenq and Shah [7] and based on water cement ratio by Ince and Alyamac [8]

\section{Repair and Rehabilitation}

The rehabilitation and reconstruction of civil infrastructure is becoming a major problem worldwide. New materials and improved cost-effective techniques to rehabilitate and strengthen infrastructure in an innovative manner are urgently sought. The traditional techniques used steel plates or externally post-tensioned cables in the past to improve the structural performance of concrete structures and strengthen deteriorated bridges [9]. However, these traditional techniques have drawbacks like, high installation cost, weight and the corrosion of the plates that could adversely affect the bond strength. Normally repair/or rehabilitation is done externally or internally (partial replacement of concrete).

\subsection{Concrete Cracks}

Cracks are the most frequent and easily recognizable sign of concrete problems. Because the tensile strength of concrete is only about one-tenth of its strength in compression, concrete tends to crack and break when subjected to large loads. In reinforced-concrete structures, the role of resisting tensile stresses belongs to steel reinforcement.

Cracks can occur for a variety of reasons. Minor flexural cracks are a part of normal concrete behavior. Heavy cracks occur when the reinforcement fails, either because the bars are placed incorrectly or because the member sustains damage. Also, many cracks occur while concrete is still wet and has not yet formed a monolithic whole with the steel reinforcement [10].

Self-healing techniques are known methods to cease cracking and to regain the strength and durability of concrete [11-12]. The geometry and size of cracks have an important role in selecting self-healing techniques and agents/materials [13] and thereby there is a need to study in detail about the size and opening of the crack to apply any advanced technology.

\subsection{Dormant and Active Cracks}

Cracks in concrete can be divided into two major classes: dormant and active. Once formed, dormant cracks do not increase in size and length. As the name suggests, active cracks change their width or length under load. Dormant cracks typically result from shrinkage, initial movement of supports, or previous structural overload. Depending on their size and location, they may or may not need repair. On the other hand, active cracks are usually formed in response to a continuing movement or present overload; they open and close because of external forces. Repairing active cracks is difficult.

Cracks that significantly reduce the structural capacity of the member need to be repaired. The first step in assessing the need for repair is to diagnose the cause and to identify cracks that are overly wide or structural in nature. Any cracks in flexural members should be investigated especially carefully. Transverse cracks in beams and frame columns reduce their stiffness and durability, even if the strength is not affected, and should, in most cases, be fixed [14].

\section{Methodology}

Figure 1 shows the concrete model of the beam with a crack in the tension zone. Figure 2 shows the concrete patch model which is taken from tension zone for analysis, in which $\mathrm{W}_{\mathrm{c}}$ represents the crack width and $\mathrm{C}_{\mathrm{o}}$ represents the crack opening. The length and breadth of the model is $80 \mathrm{~mm}$ and $20 \mathrm{~mm}$ respectively. The variables taken into account for analysis are crack opening, (width of the crack)/(width of the beam) ie $\mathrm{W}_{\mathrm{c}} / \mathrm{W}_{\mathrm{b}}$ ratio and modulus of elasticity. Stress is applied up to the failure of the model in ANSYS and the type of load used is pressure on lines [15]. 


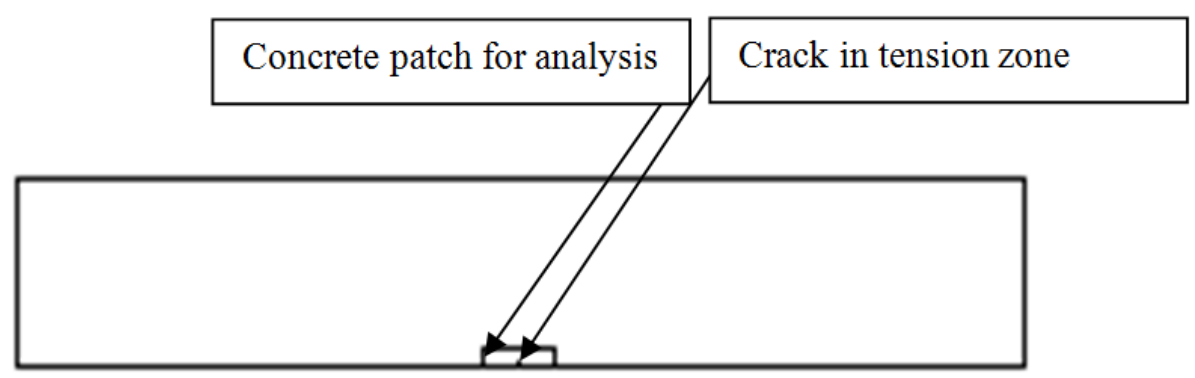

Figure 1. Model of concrete beam with crack

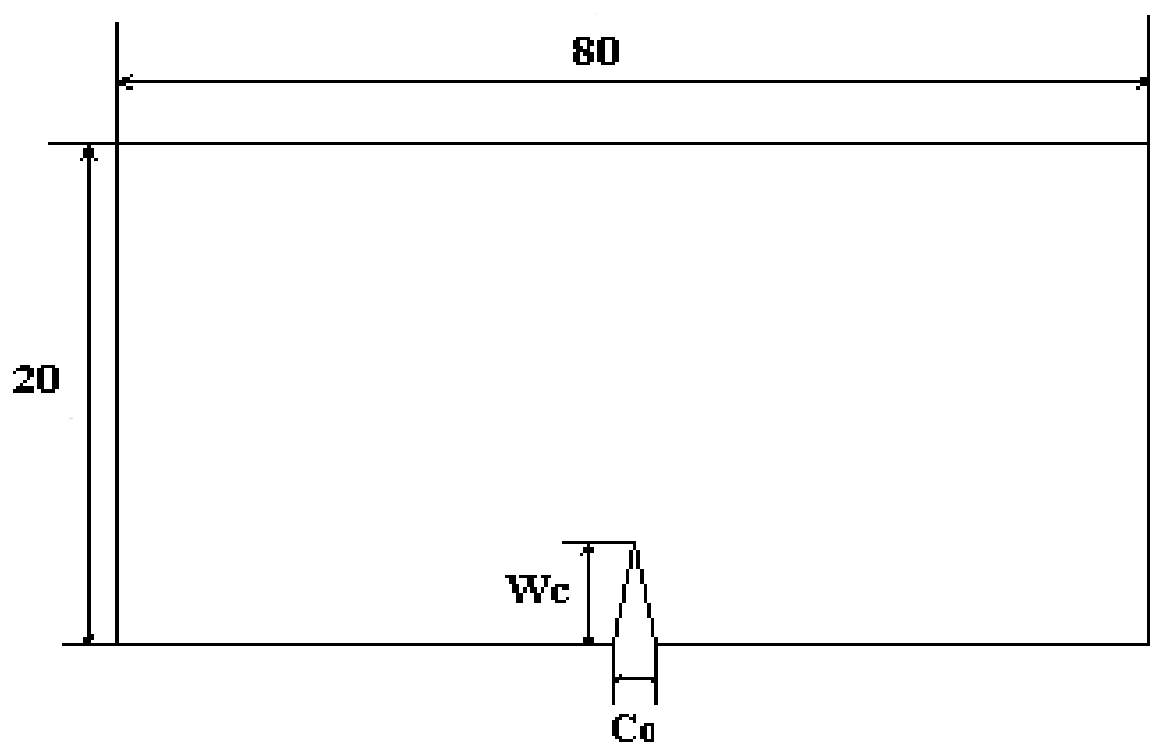

Figure 2. Concrete patch model

In this paper, tensile load is considered for analysis. It is not possible to use the normal stress-strain graph for analysis. So, it is more important to find the stress-strain values for the input tensile load. Normally in concrete, the strain was transformed from 0.002 to 0.0035 by a factor of 1.75. The assumption made here is variation of strain in tension is similar to that of compression.

The 8-noded PLANE 82 element is used in the analysis and defined by eight nodes having two degrees of freedom at each node that is translations in the nodal $\mathrm{x}$ and $\mathrm{y}$ directions. It provides more accurate results for mixed (quadrilateral-triangular) automatic meshes and has compatible displacement shapes and is well suited to model curved boundaries.

Different cases of analysis are done for uncracked and cracked models. Ecc is the Young's modulus of concrete of compressive strength $30 \mathrm{~N} / \mathrm{mm}^{2}$ and is found to be 27386 $\mathrm{N} / \mathrm{mm}^{2}$ as per International Building Code (2018) [16]. Ec is the Young's modulus of model or specimen. Table 1 shows the compressive stress $\left(f_{c k}\right)$ taken for uncracked and cracked (damaged) model.
Table 1. Compressive stress for different damage levels $\left(\mathrm{E}_{\mathrm{cc}} / \mathrm{E}_{\mathrm{c}}\right)$

\begin{tabular}{cc}
\hline Case & $\mathbf{f}_{\mathbf{c k}}\left(\mathbf{N} / \mathbf{m m}^{\mathbf{2}}\right)$ \\
\hline $\mathrm{E}_{\mathrm{cc}} / \mathrm{E}_{\mathrm{c}}=1$ & 30 \\
\hline $\mathrm{E}_{\mathrm{cc}} / \mathrm{E}_{\mathrm{c}}=0.82$ & 20 \\
\hline $\mathrm{E}_{\mathrm{cc}} / \mathrm{E}_{\mathrm{c}}=0.58$ & 10 \\
\hline
\end{tabular}

For cracked models, four cases of crack opening are considered ie $\mathrm{C}_{\mathrm{o}}=0.001,0.01,0.1$ and 1 . For each case, the ratio of $\mathrm{Ecc} / \mathrm{Ec}$ is $2,1.5,1.2,0.82$ and 0.58 where $\mathrm{Ec}$ is the Young's modulus of concrete of compressive strength $30 \mathrm{~N} / \mathrm{mm}^{2}$ Ecc is the Young's modulus of model or specimen. It is assumed that Ecc/Ec equals to 1 is uncracked model, Ecc/Ec less than 1 is damaged concrete and $\mathrm{Ecc} / \mathrm{Ec}$ greater than 1 is the material property of concrete rehabilitated with composite. So the model developed used in this paper is used for any type of composite. 


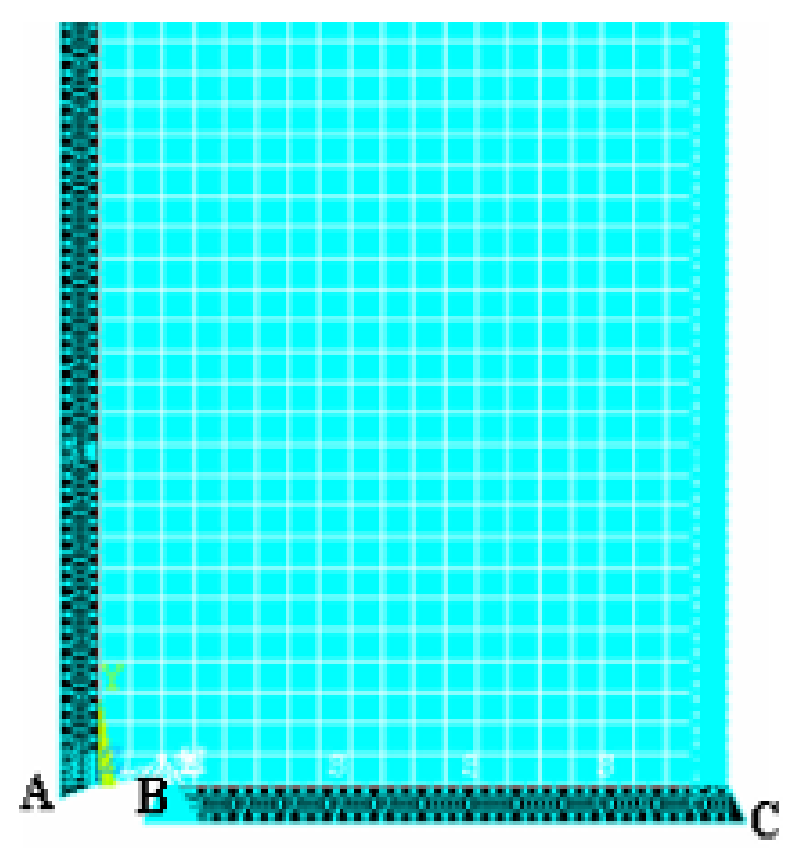

Figure 3. Model with a crack

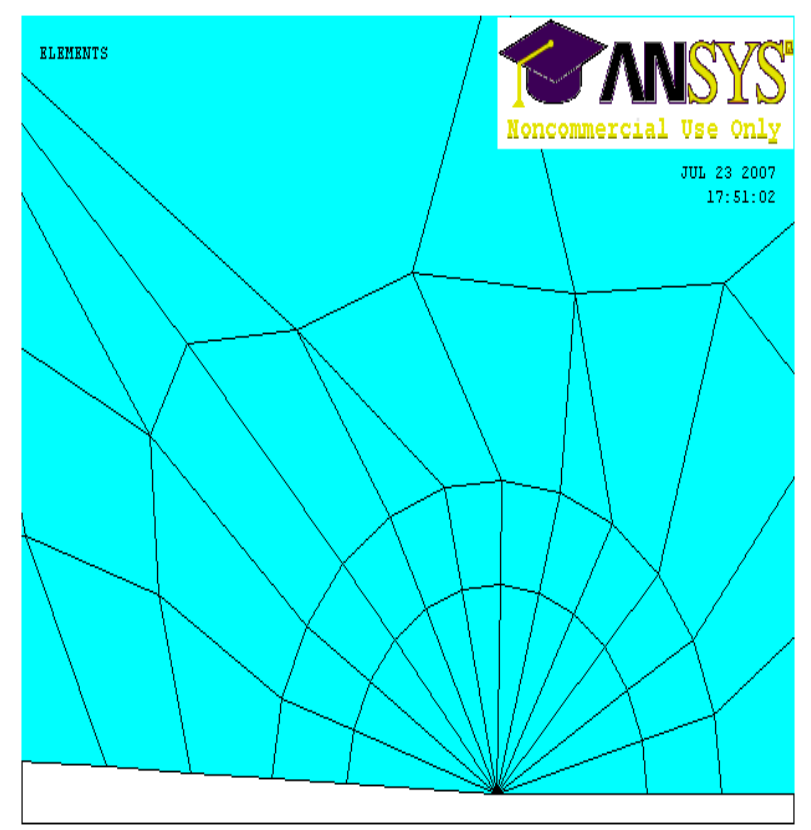

Figure 4. Triangular elements at the crack

In this model, rectangular and triangular elements are used for meshing. Rectangular elements of size 1 x 1 are used throughout the model (figure 3) except near the crack region. Near the crack tip, the variation of stress is very high and there by triangular elements are used and is shown in figure 4. They are skewed at quarter points (1/4 pts). This type of meshing is useful for modeling stress concentrations and crack tips. During meshing, elements are initially generated circumferentially about, and radially away, from the key point. Figure 5 shows the mesh pattern of concrete model with support conditions. To reduce the time period of analysis, half of the model has been analyzed by using symmetry about line option in finite element modelling. The model is subjected to tensile stress, staring with an intensity of $0.25 \mathrm{~N} / \mathrm{mm}^{2}$, and solution converged when it reaches ultimate stress which is given as input.

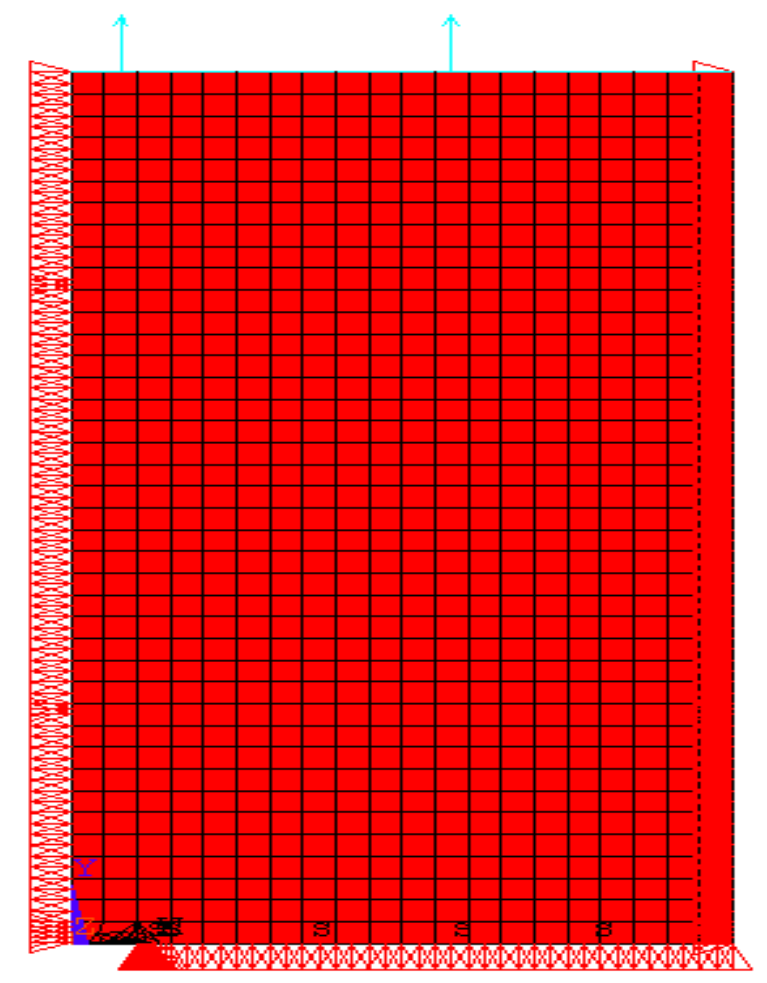

Figure 5. Concrete model with Support condition

\section{Results and Discussions}

Normally, repair for crack and damage is practically required for rehabilitation. By using results of this paper, the required type of composite for repair of the damaged and cracked beam can be easily found out. These composites should apply $1 / 8^{\text {th }}$ of the span in spanning direction up to the reinforcement level.

The percentage increase in stiffness for different combinations of crack width and crack opening of the model with different damage levels before and after cracking or rupture load are shown in figure 6 and figure. 7. The percentage decrease in displacement, for different crack width, crack opening and damage before and after cracking or rupture load are plotted in figure 8 and figure 9. The results of this analysis (Figure 6 to Figure 9), before and after the rupture load, are given as input to develop the equation for the design of composites. 


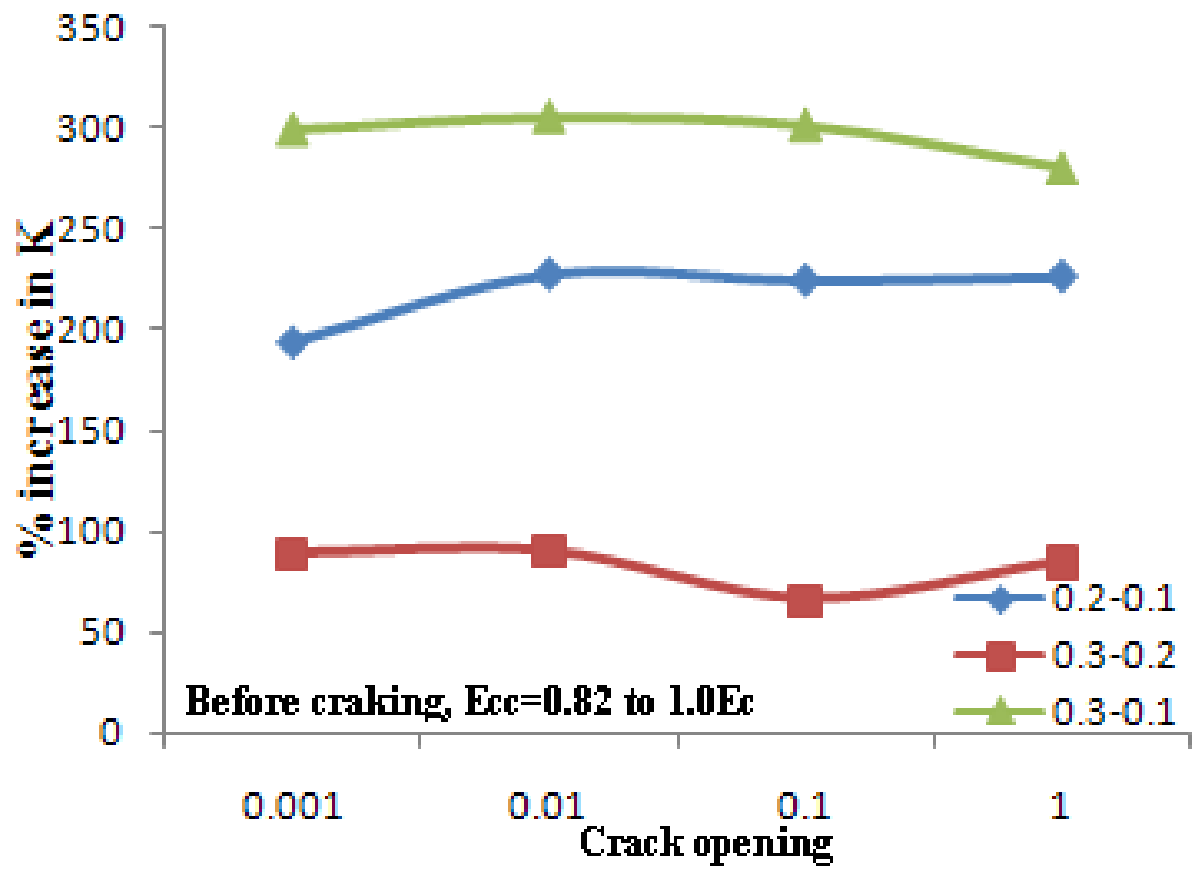

(a) Damage level $\mathrm{E}_{\mathrm{cc}} / \mathrm{E}_{\mathrm{c}}=0.82$ to 1

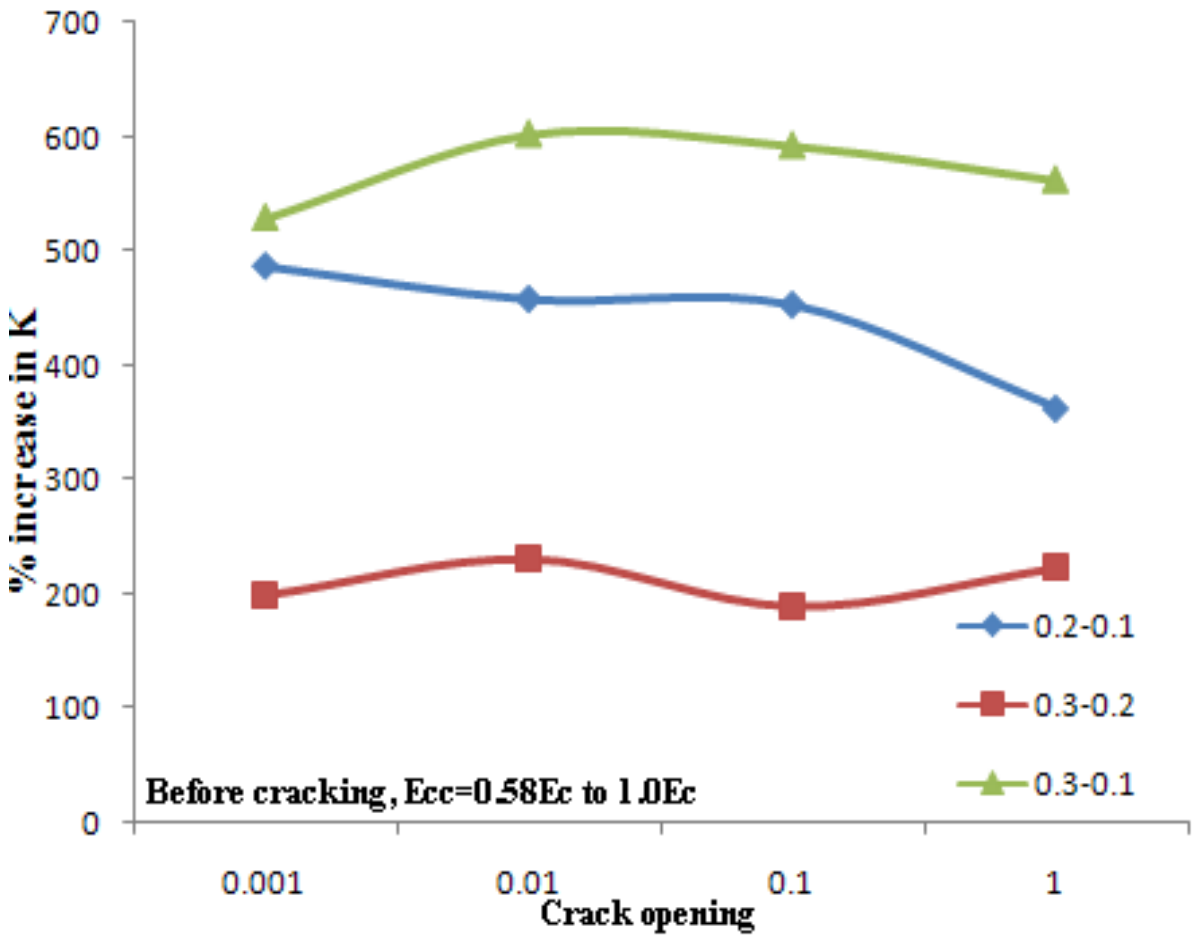

(b) Damage level $\mathrm{E}_{\mathrm{cc}} / \mathrm{E}_{\mathrm{c}}=0.58$ to 1 


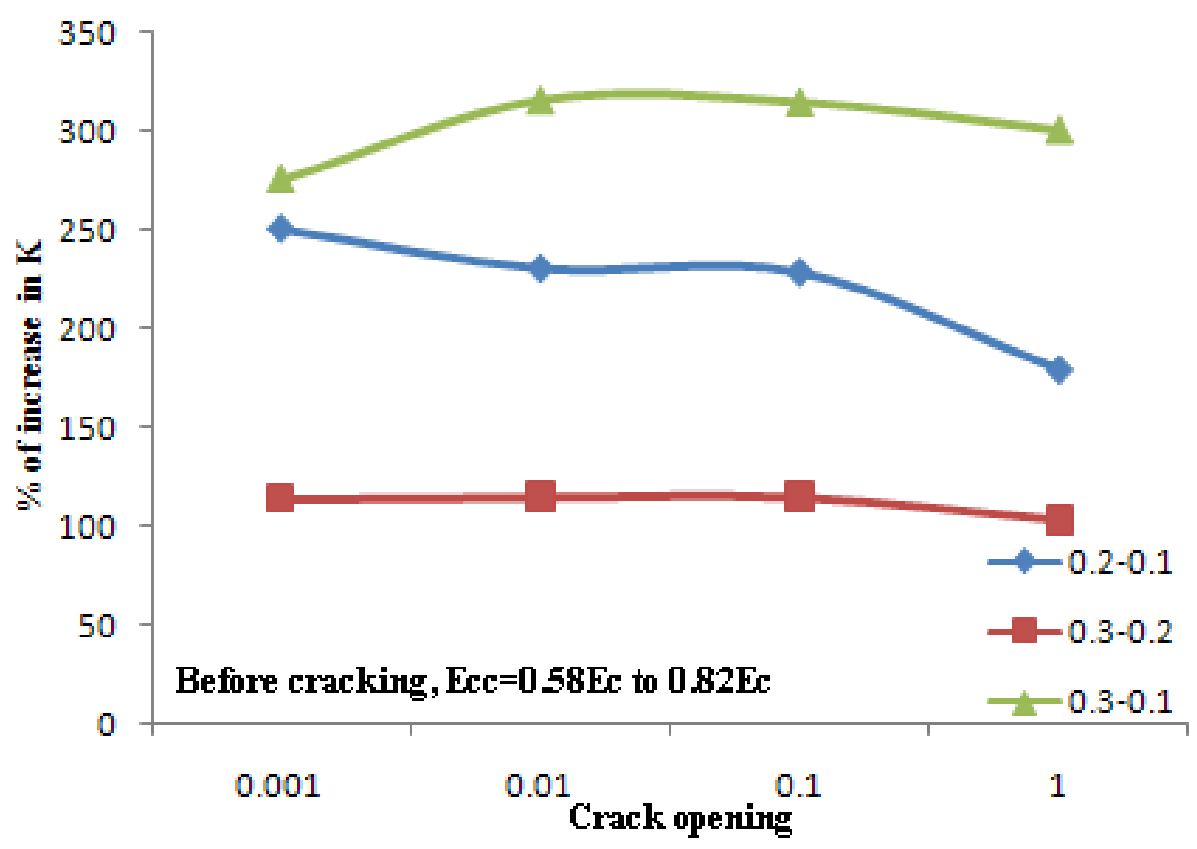

(c) Damage level $\mathrm{E}_{\mathrm{cc}} / \mathrm{E}_{\mathrm{c}}=0.58$ to 0.82

Figure 6. Percentage increase in stiffness of the model with different crack opening obtained before rupture load

Table 2. Equations for the design composites based on stiffness

\begin{tabular}{|c|c|c|c|}
\hline $\mathrm{C}_{0}$ & $\mathbf{W}_{\mathbf{c}} / \mathbf{W}_{\mathbf{b}}$ & $\begin{array}{l}\text { Type of composite (y) } \\
\text { [Before cracking] }\end{array}$ & $\begin{array}{c}\text { Type of composite (y) } \\
\text { [After cracking] }\end{array}$ \\
\hline \multirow{3}{*}{0.001} & $02-0.1$ & $y=2.9 e-5 x^{2}+5.65 e-3 x+1.36$ & $y=1.28 e-5 x^{2}+5.69 e-2 x+1.29$ \\
\hline & $0.3-0.2$ & $\mathrm{y}=1.78 \mathrm{e}-6 \mathrm{x}^{2}+8.00 \mathrm{e}-3 \mathrm{x}+1.31$ & $y=9.54 e-6 x^{2}+4.31 e-3 x+1.08$ \\
\hline & $0.3-0.1$ & $y=9.57 e-6 x^{2}+1.78 e-2 x+2.22$ & $y=3.7 e-5 x^{2}+1.2 e-2 x+1.61$ \\
\hline \multirow{3}{*}{0.01} & $02-0.1$ & $y=-1.63 e-5 x^{2}+1.42 e-2 x+1.68$ & $y=-4.66 e-5 x^{2}+1.49 e-2 x+0.867$ \\
\hline & $0.3-0.2$ & $\mathrm{y}=7.61 \mathrm{e}-6 \mathrm{x}^{2}+9.58 \mathrm{e}-3 \mathrm{x}+1.33$ & $y=1.39 e-6 x^{2}+4.98 e-3 x+0.998$ \\
\hline & $0.3-0.1$ & $y=3.53 e-5 x^{2}+2.41 e-2 x+2.50$ & $y=0.0074 x+1.6766$ \\
\hline \multirow{3}{*}{0.1} & $02-0.1$ & $y=1.86 e-5 x^{2}+1.43 e-2 x+1.68$ & $y=1.32 e-5 x^{2}+5.23 e-3 x+1.26$ \\
\hline & $0.3-0.2$ & $y=8.59 e-6 x^{2}+7.91 e-3 x+1.21$ & $y=1.38 e-5 x^{2}+1.76 e-3 x+1.09$ \\
\hline & $0.3-0.1$ & $\mathrm{y}=4.91 \mathrm{e}-5 \mathrm{x}^{2}+2.49 \mathrm{e}-2 \mathrm{x}+2.50$ & $y=6.55 e-5 x^{2}+1.13 e-2 x+1.51$ \\
\hline \multirow{3}{*}{1} & $02-0.1$ & $y=1.78 e-5 x^{2}+1.4 e-2 x+1.65$ & $y=1.09 e-5 x^{2}+5.19 e-3 x+1.24$ \\
\hline & $0.3-0.2$ & $y=-8.53 e-5 x^{2}+1.4 e-2 x+1.40$ & $y=3.55 e-6 x^{2}+4.22 e-3 x+1.00$ \\
\hline & $0.3-0.1$ & $y=-3.56 e-4 x^{2}-6.63 e-3 x+2.0$ & $y=3.26 e-5 x^{2}+1.09 e-2 x+1.5$ \\
\hline
\end{tabular}

\subsection{Equations for the Design of Composites}

Table 2 gives the equations to choose the type of composite for repair /or rehabilitation for different combination of crack opening, crack width ratio and damage levels based on stiffness obtained before and after the rupture load of the model.
The value in percentage of increase in stiffness $(x)$ can be noted from figure 6 and figure 7 for different cases. By substituting the values in the equations given in Table 2, the required type of composite to be used for repair/or rehabilitation (y) can be found out. These composites need to be applied in the $1 / 8^{\text {th }}$ of the span in spanning direction up to the reinforcement level. 


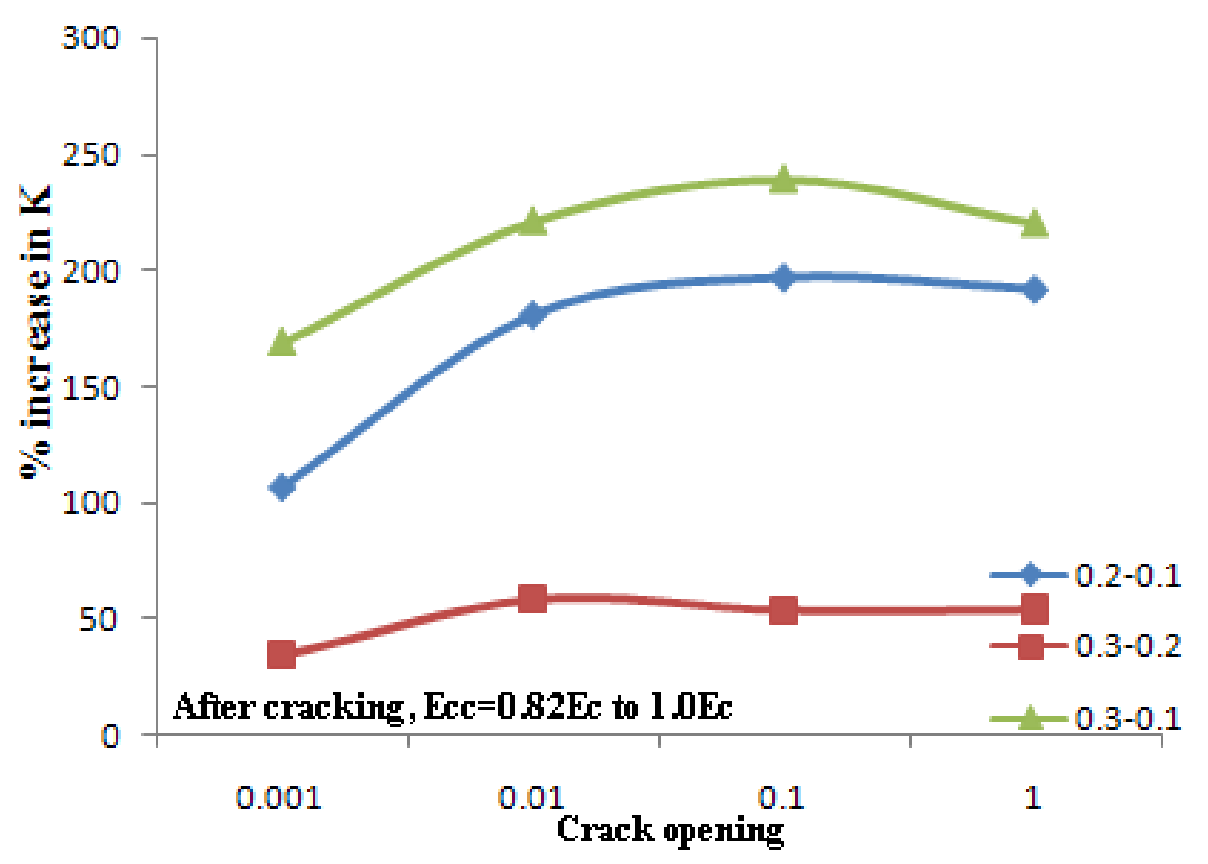

(a) Damage level $\mathrm{E}_{\mathrm{cc}} / \mathrm{E}_{\mathrm{c}}=0.82$ to 1

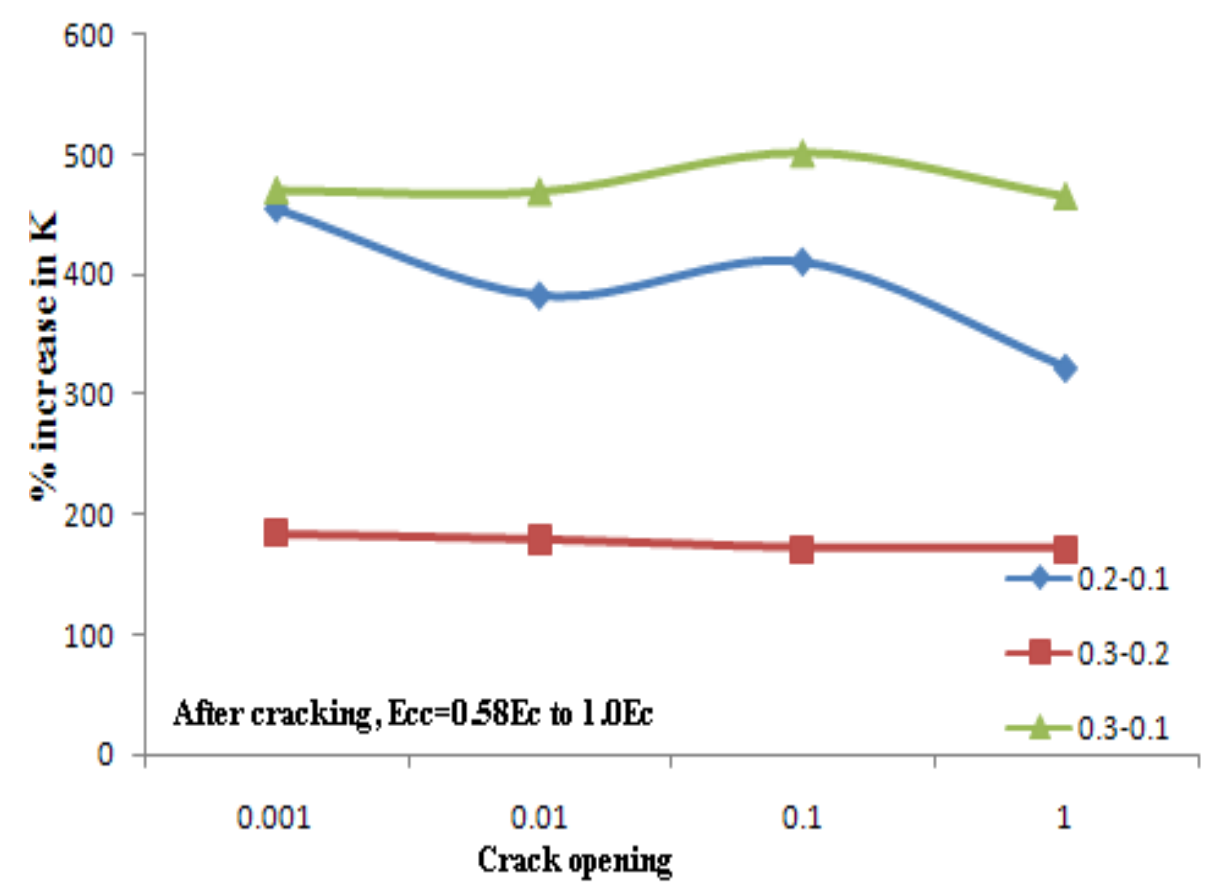

(b) Damage level $\mathrm{E}_{\mathrm{cc}} / \mathrm{E}_{\mathrm{c}}=0.58$ to 1 


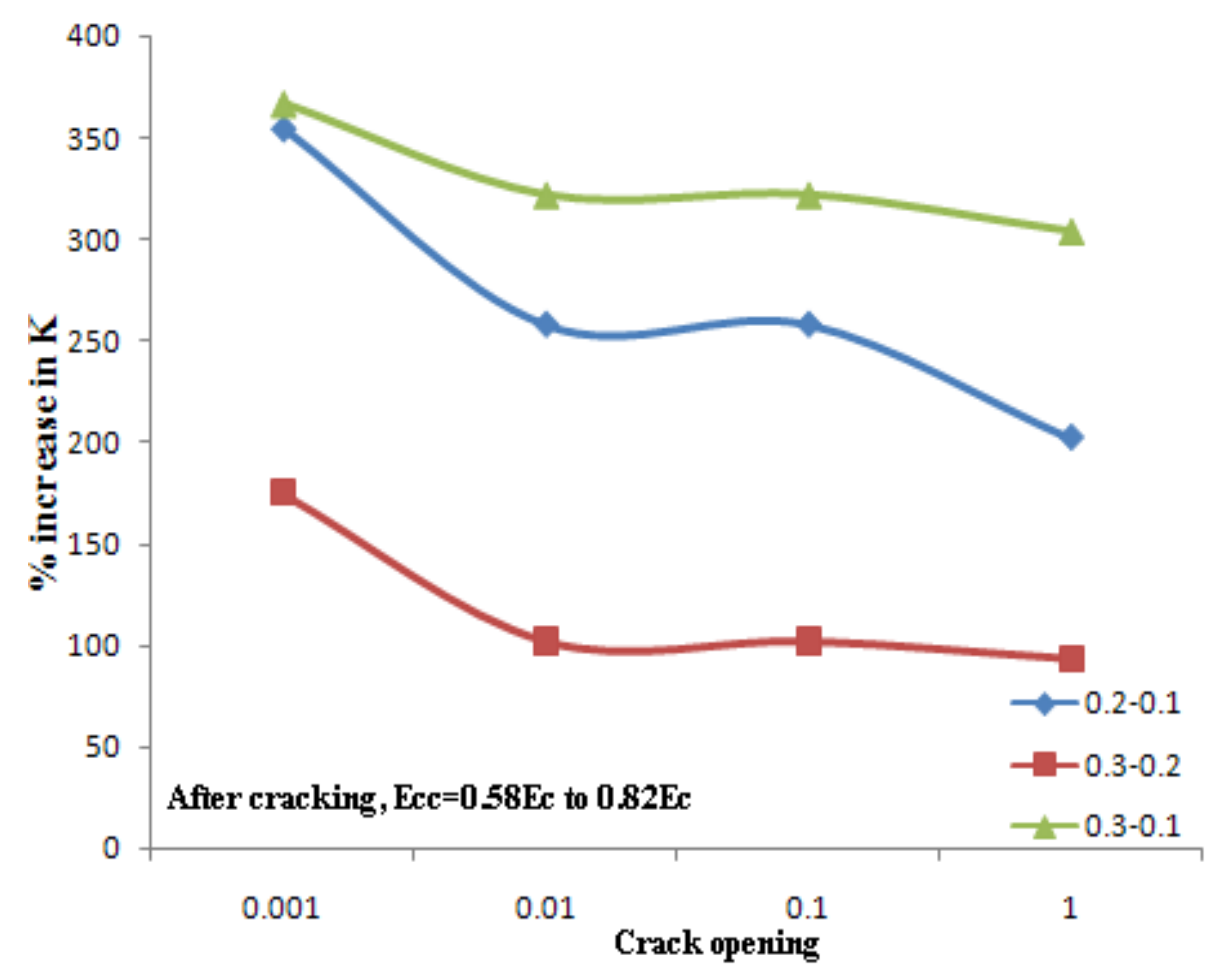

(c) Damage level $\mathrm{E}_{\mathrm{cc}} / \mathrm{E}_{\mathrm{c}}=0.58$ to 0.82

Figure 7. Percentage increase in stiffness of the model with different crack opening obtained after rupture load

Table 3. Equations for the design composites based on displacement

\begin{tabular}{|c|c|c|c|}
\hline $\mathbf{C}_{\mathbf{o}}$ & $\mathbf{W}_{\mathbf{c}} / \mathbf{W}_{\mathbf{b}}$ & $\begin{array}{l}\text { Type of composite (y) } \\
\text { [Before cracking] }\end{array}$ & $\begin{array}{l}\text { Type of composite (y) } \\
\text { [After cracking] }\end{array}$ \\
\hline \multirow{3}{*}{0.001} & $02-0.1$ & $y=1.06 e-4 x^{2}+1.48 e-2 x+1.69$ & $\mathrm{y}=1.97 \mathrm{e}-4 \mathrm{x}^{2}+5.63 \mathrm{e}-3 \mathrm{x}+1.23$ \\
\hline & $0.3-0.2$ & $\mathrm{y}=1.84 \mathrm{e}-4 \mathrm{x}^{2}+9.89 \mathrm{e}-3 \mathrm{x}+1.31$ & $\mathrm{y}=4.63 \mathrm{e}-4 \mathrm{x}^{2}-1.81 \mathrm{e}-2 \mathrm{x}+1.38$ \\
\hline & $0.3-0.1$ & $y=4.11 e-5 x^{2}+1.38 e-2 x+2.34$ & $\mathrm{y}=1.17 \mathrm{e}-4 \mathrm{x}^{2}+1.42 \mathrm{e}-2 \mathrm{x}+1.63$ \\
\hline \multirow{3}{*}{0.01} & $02-0.1$ & $y=1.06 e-4 x^{2}+1.42 e-2 x+1.68$ & $\mathrm{y}=1.20 \mathrm{e}-4 \mathrm{x}^{2}+1.09 \mathrm{e}-2 \mathrm{x}+1.36$ \\
\hline & $0.3-0.2$ & $y=1.86 e-4 x^{2}+9.89 e-3 x+1.31$ & $y=2.5 e-4 x^{2}+1.39 e-3 x+1.19$ \\
\hline & $0.3-0.1$ & $\mathrm{y}=4.15 \mathrm{e}-5 \mathrm{x}^{2}+1.39 \mathrm{e}-2 \mathrm{x}+2.3$ & $\mathrm{y}=6.12 \mathrm{e}-5 \mathrm{x}^{2}+1.32 \mathrm{e}-2 \mathrm{x}+1.90$ \\
\hline \multirow{3}{*}{0.1} & $02-0.1$ & $y=1.09 e-4 x^{2}+1.5 e-2 x+1.69$ & $y=1.24 e-4 x^{2}+1.08 e-2 x+1.43$ \\
\hline & $0.3-0.2$ & $y=2.52 e-4 x^{2}+4.67 e-3 x+1.21$ & $\mathrm{y}=4.29 \mathrm{e}-4 \mathrm{x}^{2}-1.05 \mathrm{e}-2 \mathrm{x}+1.26$ \\
\hline & $0.3-0.1$ & $\mathrm{y}=4.31 \mathrm{e}-5 \mathrm{x}^{2}+1.41 \mathrm{e}-2 \mathrm{x}+2.35$ & $\mathrm{y}=8.84 \mathrm{e}-5 \mathrm{x}^{2}+1.66 \mathrm{e}-2 \mathrm{x}+1.97$ \\
\hline \multirow{3}{*}{1} & $02-0.1$ & $\mathrm{y}=1.12 e-4 \mathrm{x}^{2}+1.49 \mathrm{e}-2 \mathrm{x}+1.67$ & $\mathrm{y}=1.35 \mathrm{e}-4 \mathrm{x}^{2}+1.04 \mathrm{e}-2 \mathrm{x}+1.40$ \\
\hline & $0.3-0.2$ & $y=1.62 e-5 x^{2}+1.41 e-2 x+1.41$ & $\mathrm{y}=3.47 \mathrm{e}-4 \mathrm{x}^{2}-4.46 \mathrm{e}-3 \mathrm{x}+1.21$ \\
\hline & $0.3-0.1$ & $y=3.37 e-6 x^{2}+7.6 e-3 x+2.17$ & $y=8 e-5 x^{2}+1.51 e-2 x+1.92$ \\
\hline
\end{tabular}

Table 3 gives the equations to choose the type of composite for repair /or rehabilitation for different combination of crack opening, crack width ratio and damage levels based on displacement obtained before and after the rupture load of the model.

The value in percentage of decrease in displacement (x) is found in figure 8 and figure 9 for different cases. By substituting the values in the equations given in Table 3 , the required type of composite for repair/or rehabilitation (y) can be found out.
For example, using nondestructive tests it is found that the crack opening is 0.01 and crack width varies from 0.1 to 0.3 , the grade of concrete is $25 \mathrm{~N} / \mathrm{mm}^{2}$. If this grade is normalized with M30 grade concrete, the damage level varies from 0.82 to 1 .

From figure 6 (a) and figure 7 (a), the percentage increase in stiffness is found to be $225 \%$ before cracking or rupture and $300 \%$ after cracking or rupture. By substituting the values in the equation provided in Table 2, the young's modulus of the composite to be used for rehabilitation varies from 2.3 to $2.5 \mathrm{ie} \mathrm{Ecc} / \mathrm{Ec}=2.3$ to 2.5 . 


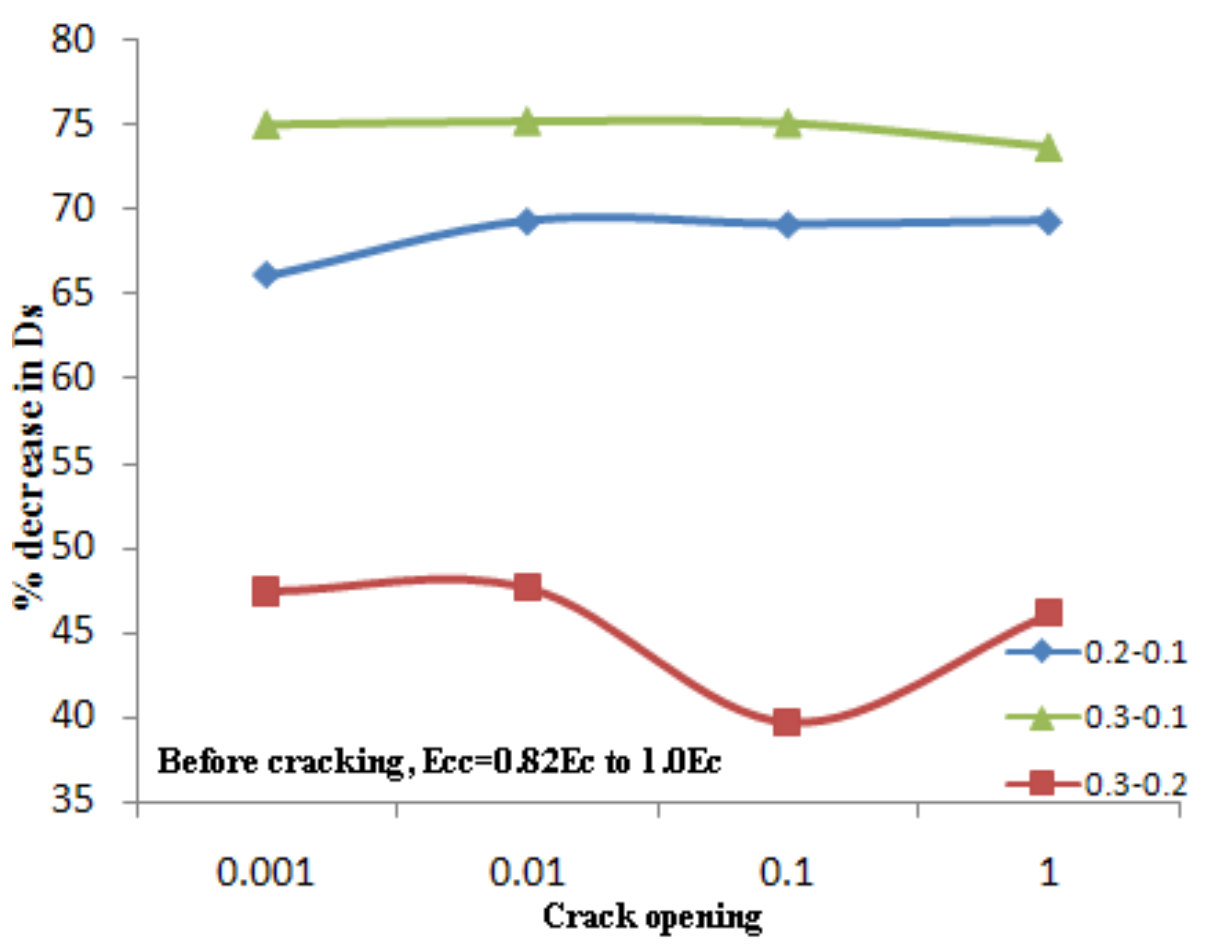

(a) Damage level $\mathrm{E}_{\mathrm{cc}} / \mathrm{E}_{\mathrm{c}}=0.82$ to 1

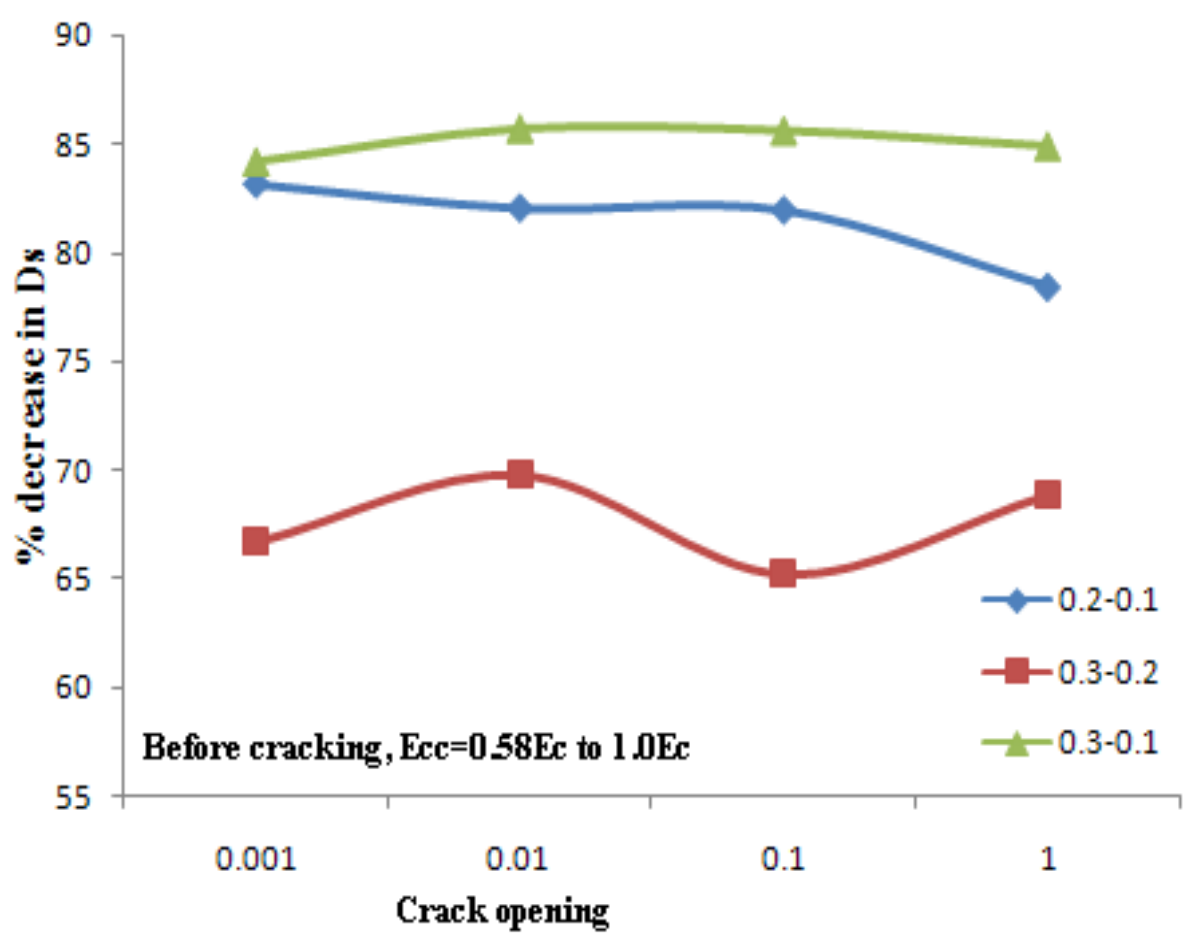

(b) Damage level $\mathrm{E}_{\mathrm{cc}} / \mathrm{E}_{\mathrm{c}}=0.58$ to 1 


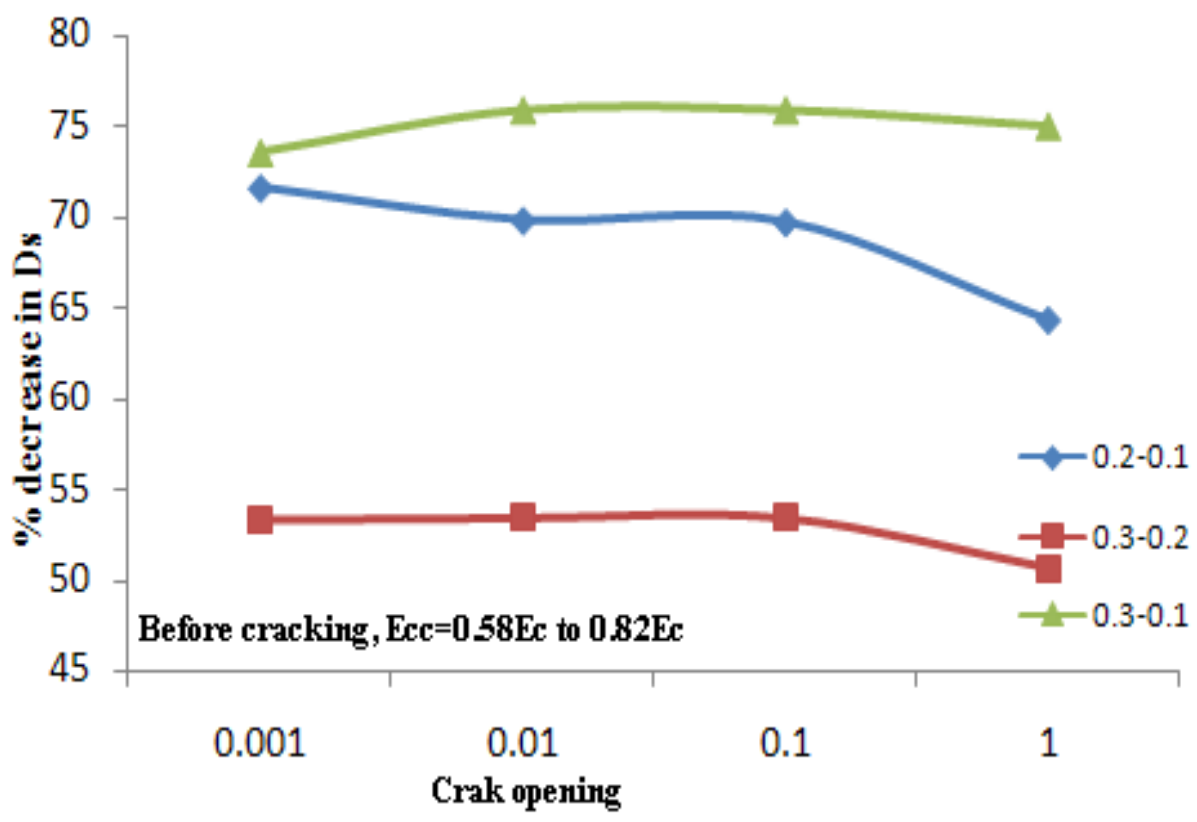

(c) Damage level $\mathrm{E}_{\mathrm{cc}} / \mathrm{E}_{\mathrm{c}}=0.58$ to 0.82

Figure 8. Percentage decrease in displacement of the model with different crack opening obtained before rupture load

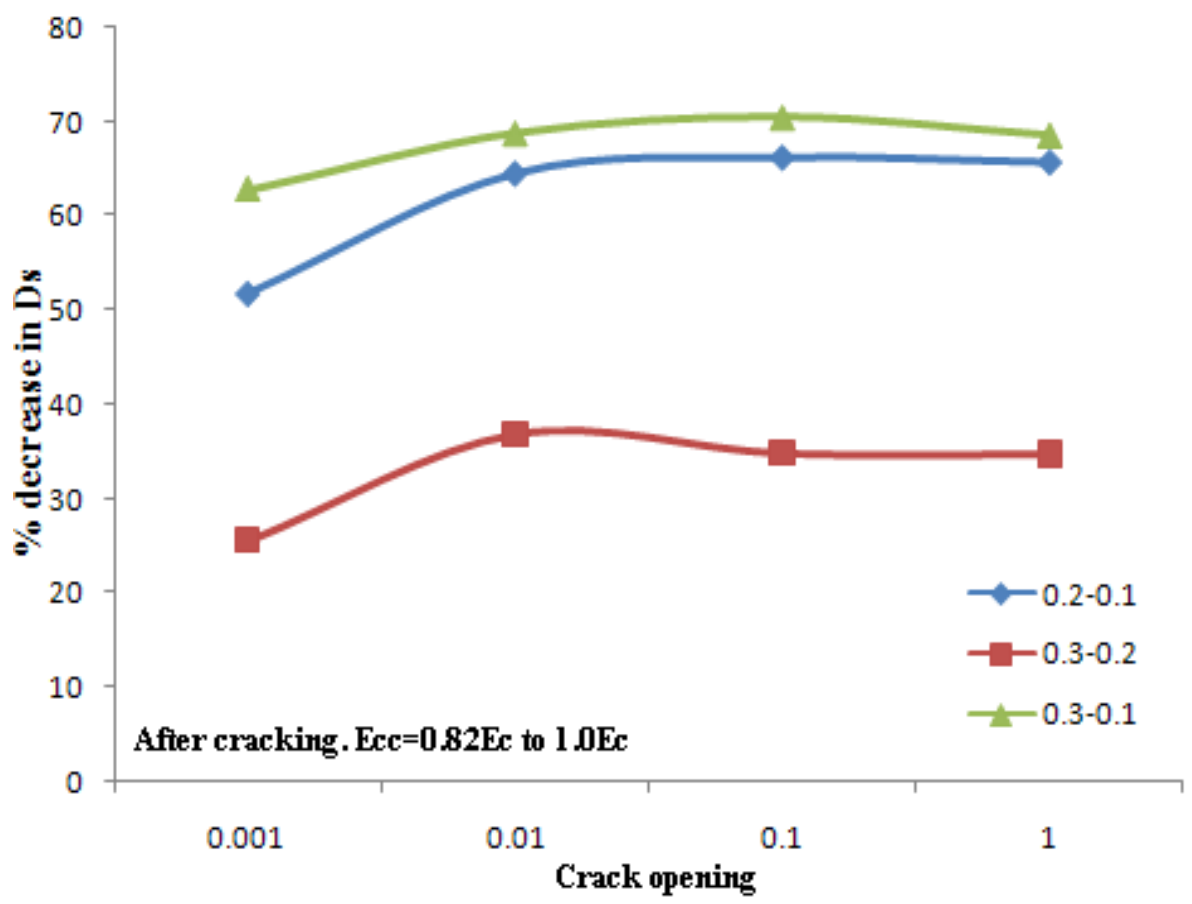

(a) Damage level $\mathrm{E}_{\mathrm{cc}} / \mathrm{E}_{\mathrm{c}}=0.82$ to 1 


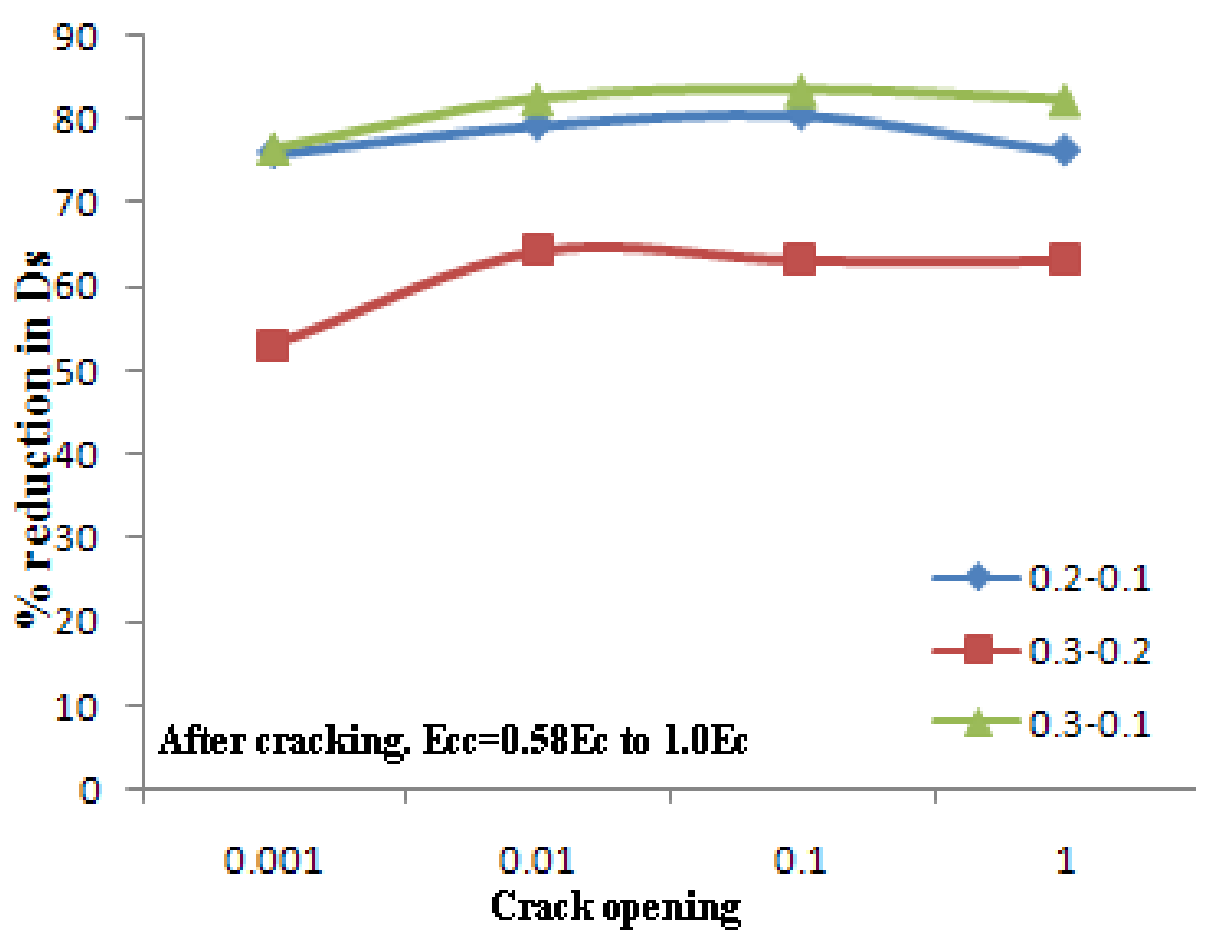

(b) Damage level $\mathrm{E}_{\mathrm{cc}} / \mathrm{E}_{\mathrm{c}}=0.58$ to 1

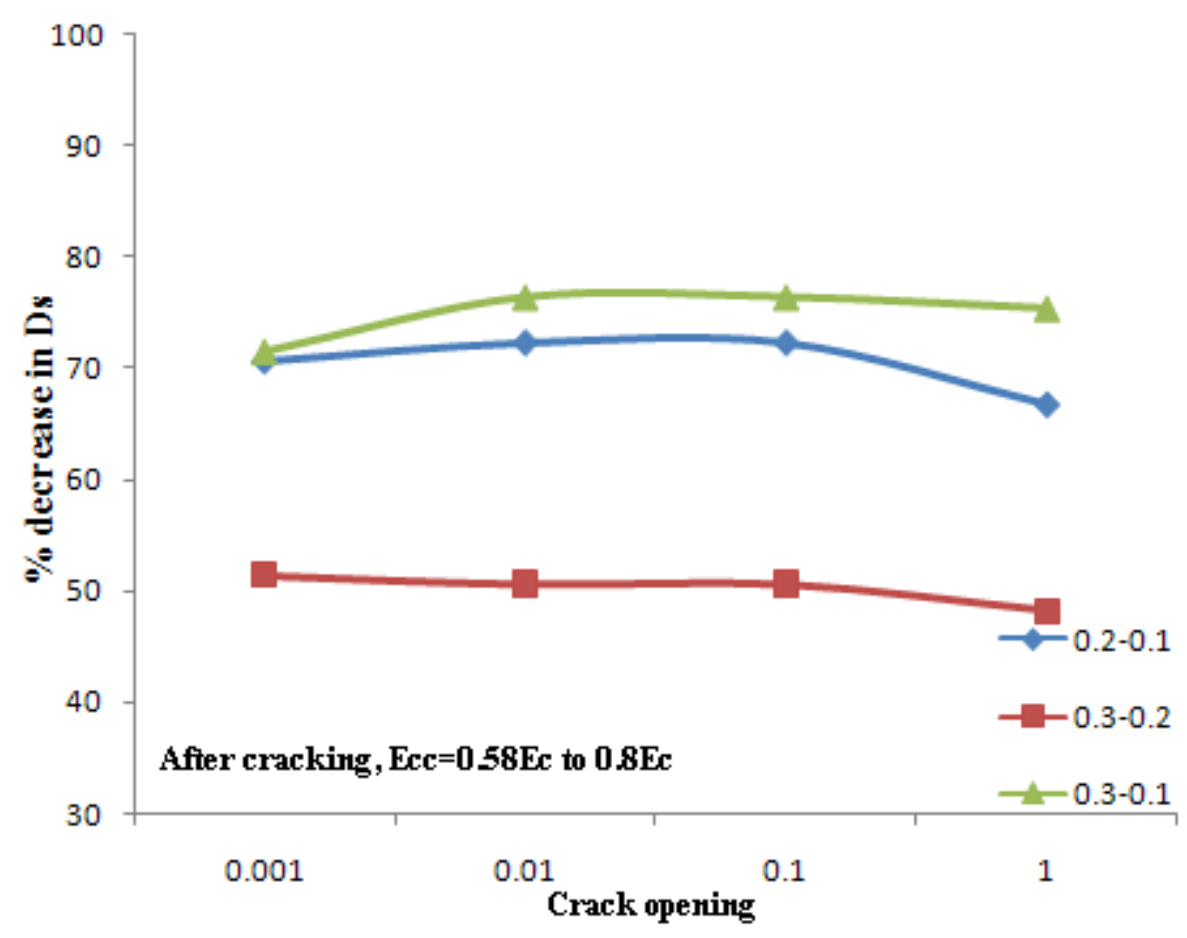

(c) Damage level $\mathrm{E}_{\mathrm{cc}} / \mathrm{E}_{\mathrm{c}}=0.58$ to 0.82

Figure 9. Percentage decrease in displacement of the model with different crack opening obtained after rupture load

Similarly, from figure $8(a)$ and figure $9(\mathrm{a})$, the percentage reduction in stiffness is found to be $65 \%$ before cracking and $75 \%$ after cracking. By substituting the values in the equation shown in Table 3, it is found that the modulus of elasticity of the composite varies from 1.9 to 2.9 with respect to the modulus of elasticity of M30 grade concrete.

The composite to be chosen for repair can be made based on displacement and stiffness. If repair is conducted for strengthening, then the result based on stiffness need to be considered and if repair is conducted to reduce the displacement, then the composite needs to be chosen based 
on displacement. Also, it is recommended to choose the better option of these two analyses (based on stiffness and displacement) for the design to be safe.

\section{Fuzzy Analysis to Handle Uncertainty}

The model developed in this paper involved a lot of uncertainties and thereby fuzzy logic has been used to handle uncertainties. Damage assessment and rehabilitation process can be modeled using fuzzy representation for input data which may be in visual or literal form and later using numeric representation as inputs. Regular engineering modeling through domain dependent finite element formulation discussed in previous sections is used to analyze the responses and these responses are later converted to literal ones which will be used to identify the types of rehabilitation.

Based on visual inspection and oral communication, further repair, rehabilitation and redesign need to be done and this necessitates use of fuzzy information processing. Fuzzy is a quick assessment based on an engineering model, to assess damage levels and to suggest rehabilitation measures, within a short period of time and this is very helpful in modern day internet and cellular communication age. Because of this, remedial measures can be done online so that dissemination is faster and mitigation efforts initiated quicker.

A simply supported beam with damage in the left beam element of spread 0.01 (figure 10) was analyzed using fuzzy logic and the surface viewer of percentage reduction in stiffness was compared with the one obtained from the novel element formulated earlier. The damage is defined by two input variables: intensity of damage and location of damage. Triangular membership function is used to define two inputs and a single output variable. Five fuzzy sets are used to define the intensity of damage namely very low, low, medium, high and very high and the universe of discourse for this variable is 0 to 90 and is shown in figure 11 (a). The second input variable location of damage is defined by four membership functions as at support, near to support, near to center and at center. Due to symmetry, the location parameter is defined only for one half span of the beam as shown in figure 11 (b). The percentage reduction in stiffness is the output variable and is defined by five membership functions namely very less, less, moderate, high and very high and is shown in figure 12 . The surface viewers obtained from fuzzy logic and from the numerical analysis of novel element developed earlier are shown in figure 13. The values obtained from fuzzy logic are closer to the results obtained from coding in which the stiffness matrix incorporates the three damage parameters, intensity, location and spread of damage. The above can be further tuned by varying the membership function for each variable and different type of damage [17].

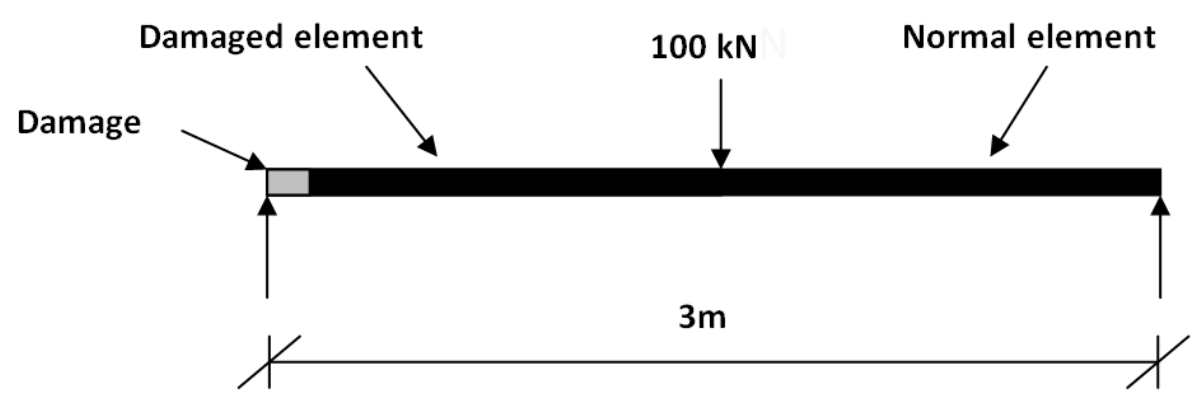

Figure 10. Simply Supported Beam with Single Damage 


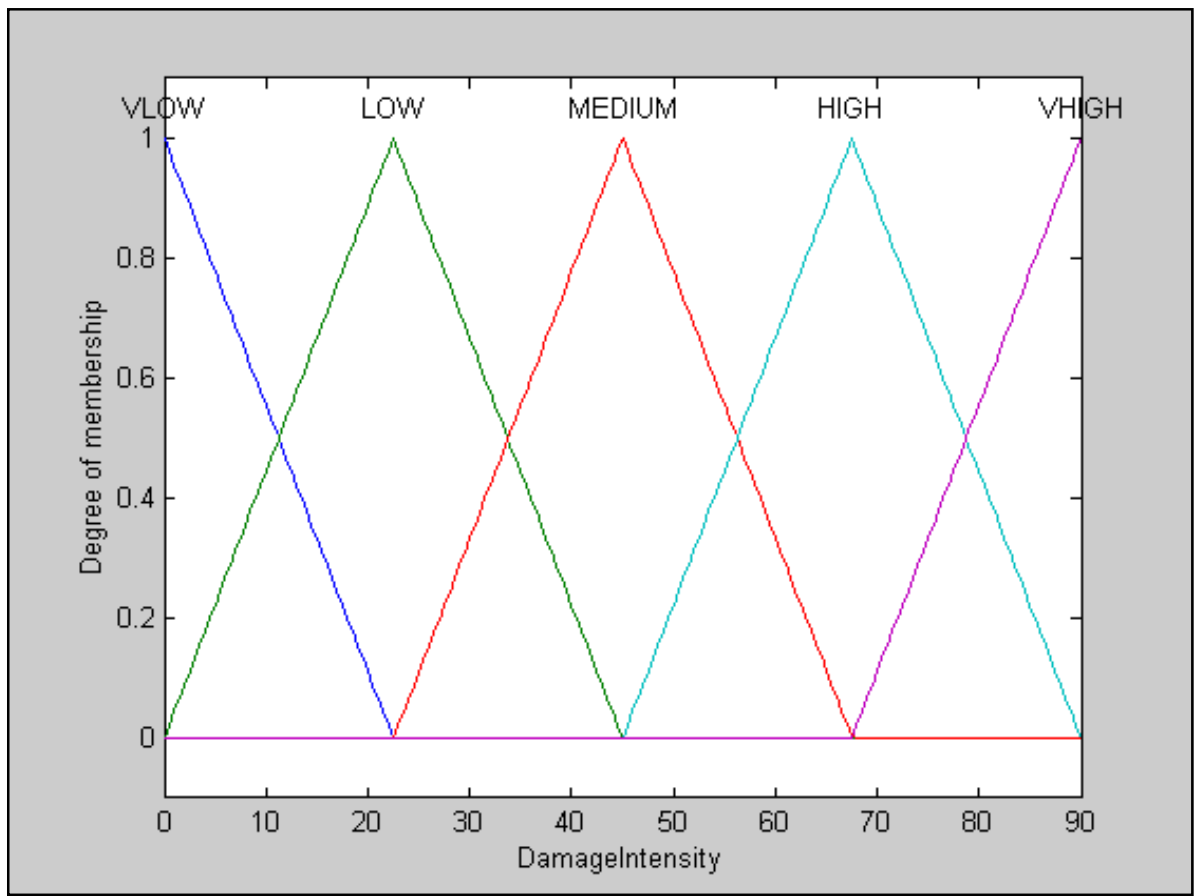

a) Intensity of Damage

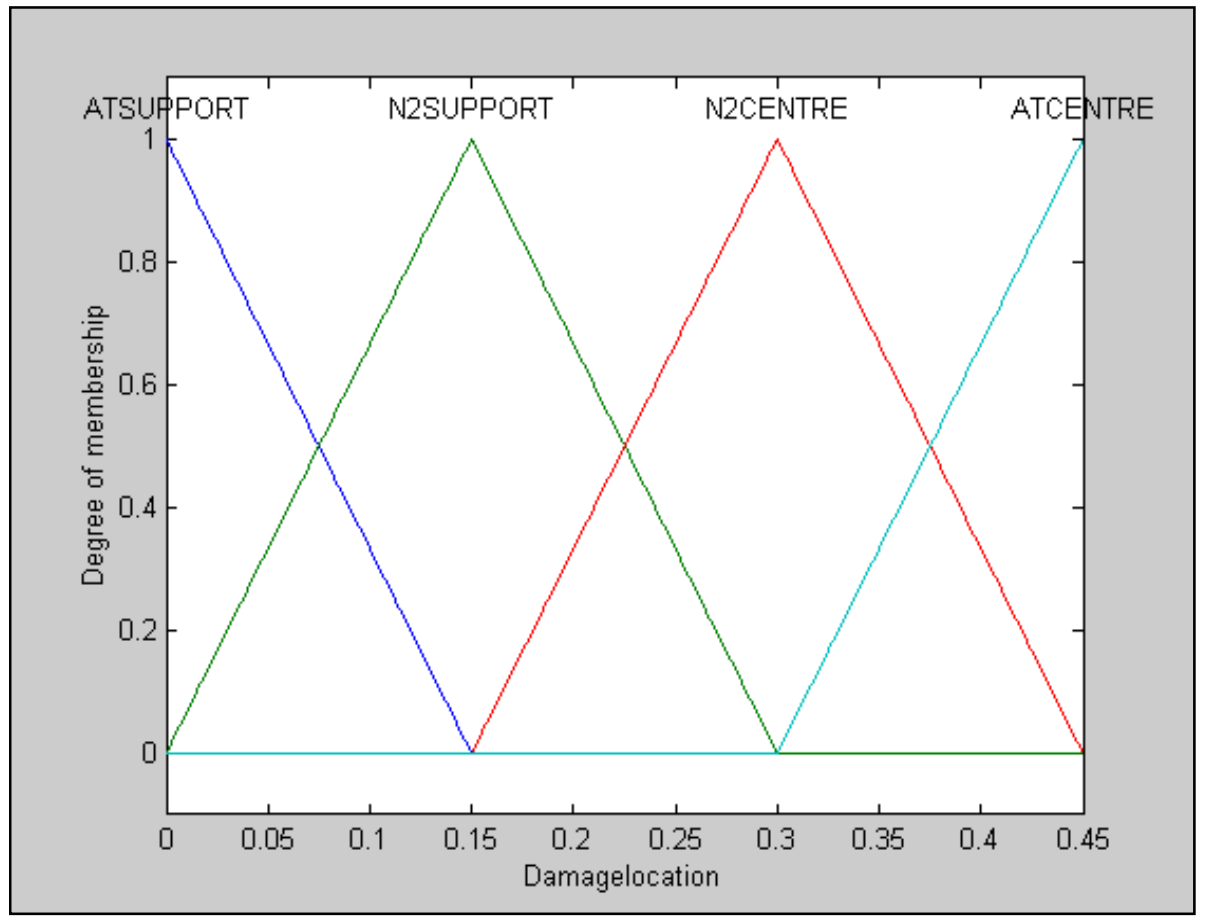

b) Location of damage

Figure 11. Membership Function of the Input Variables 


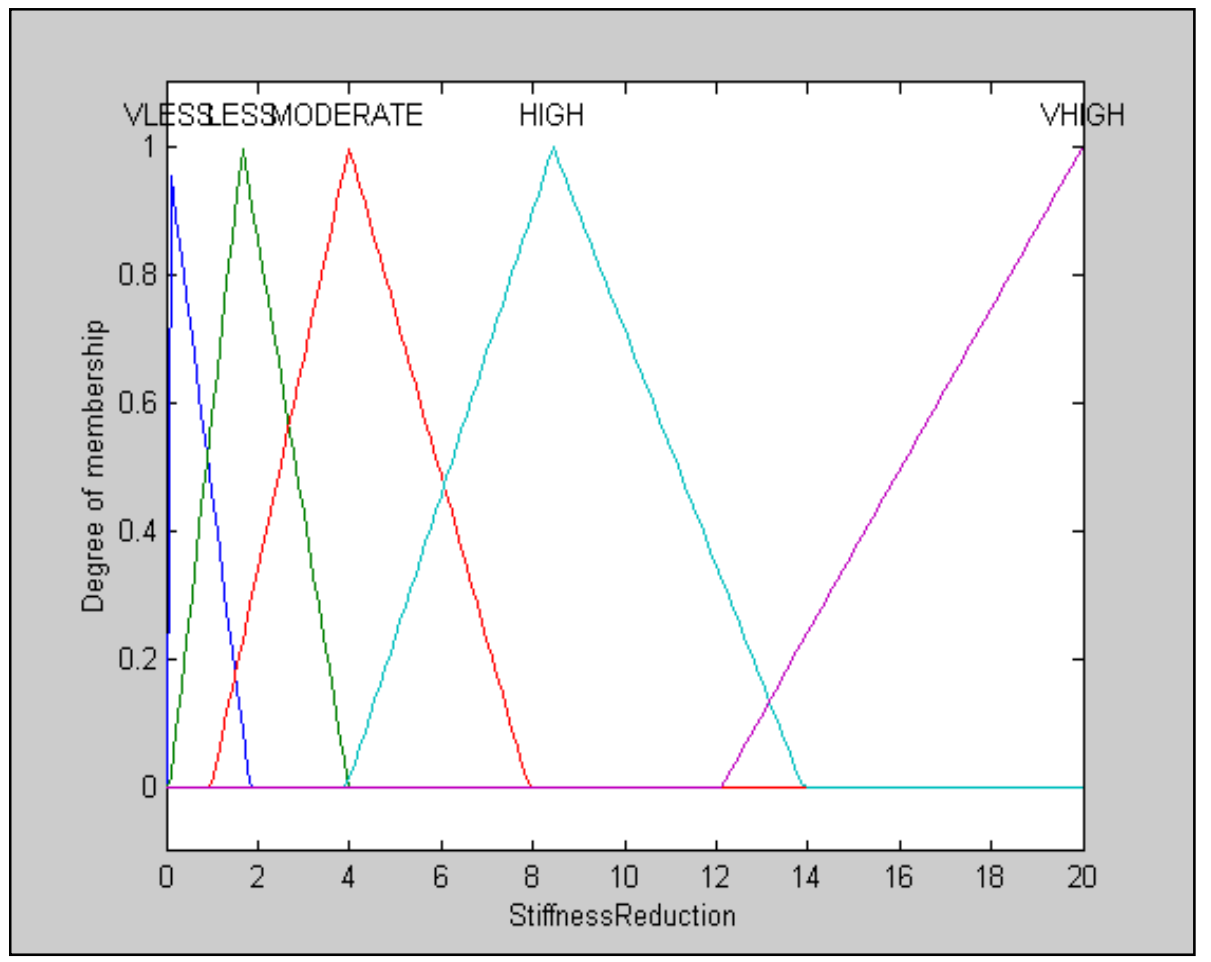

Figure 12. Membership Function of the output variable - Percentage Reduction in Stiffness

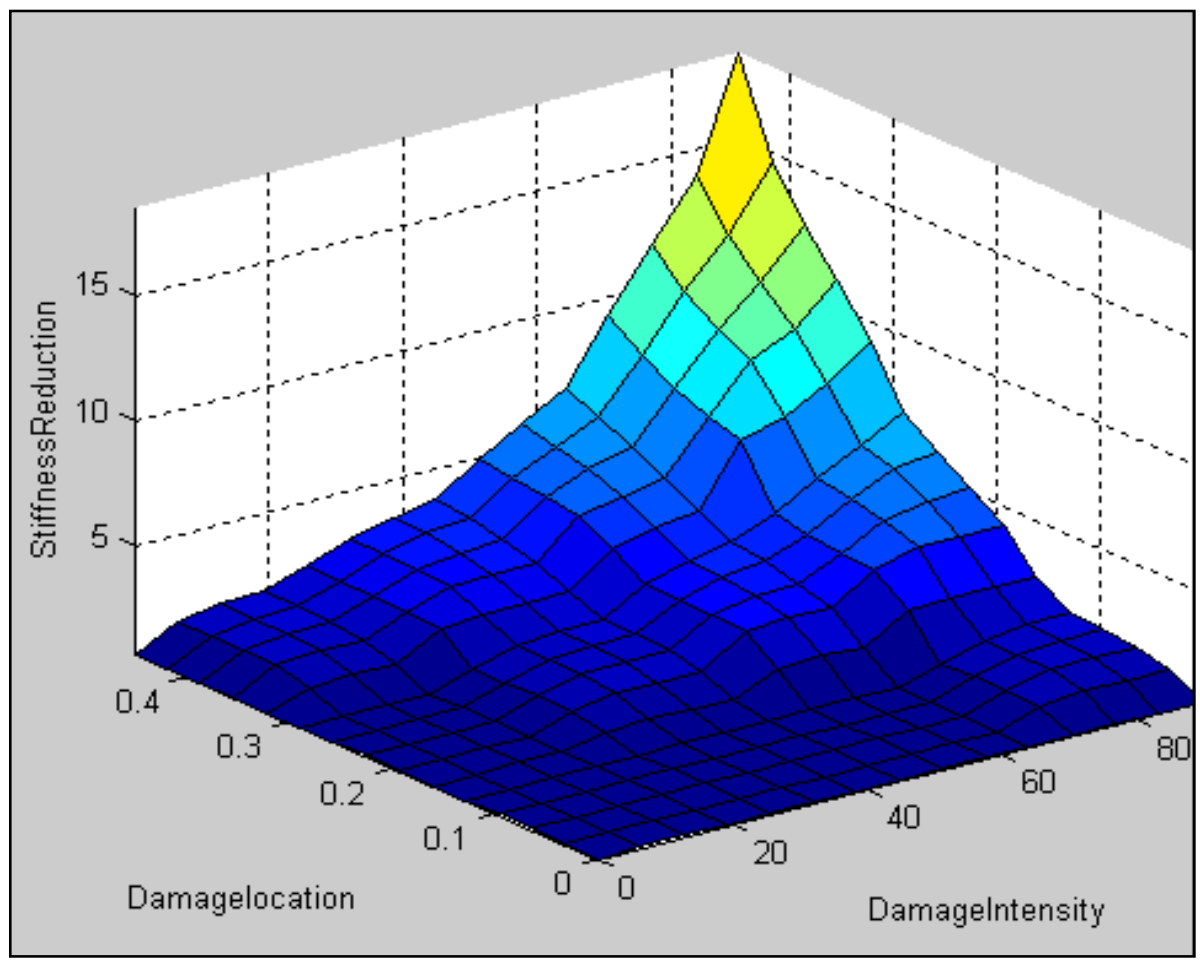

Fuzzy Analysis 


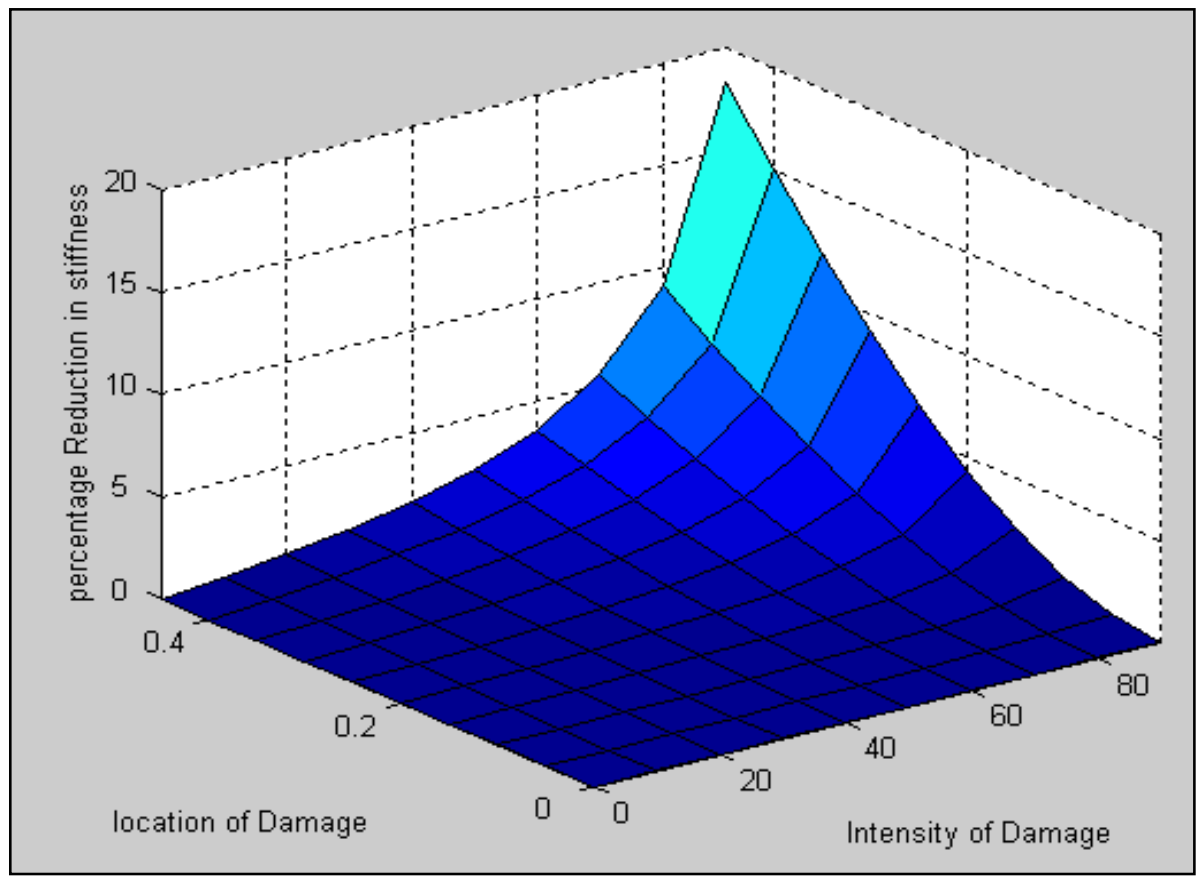

Numerical Analysis

Figure 13. Surface Viewers obtained from Fuzzy Logic and Formulated Novel Element Results for A Simply Supported Beam with Damage

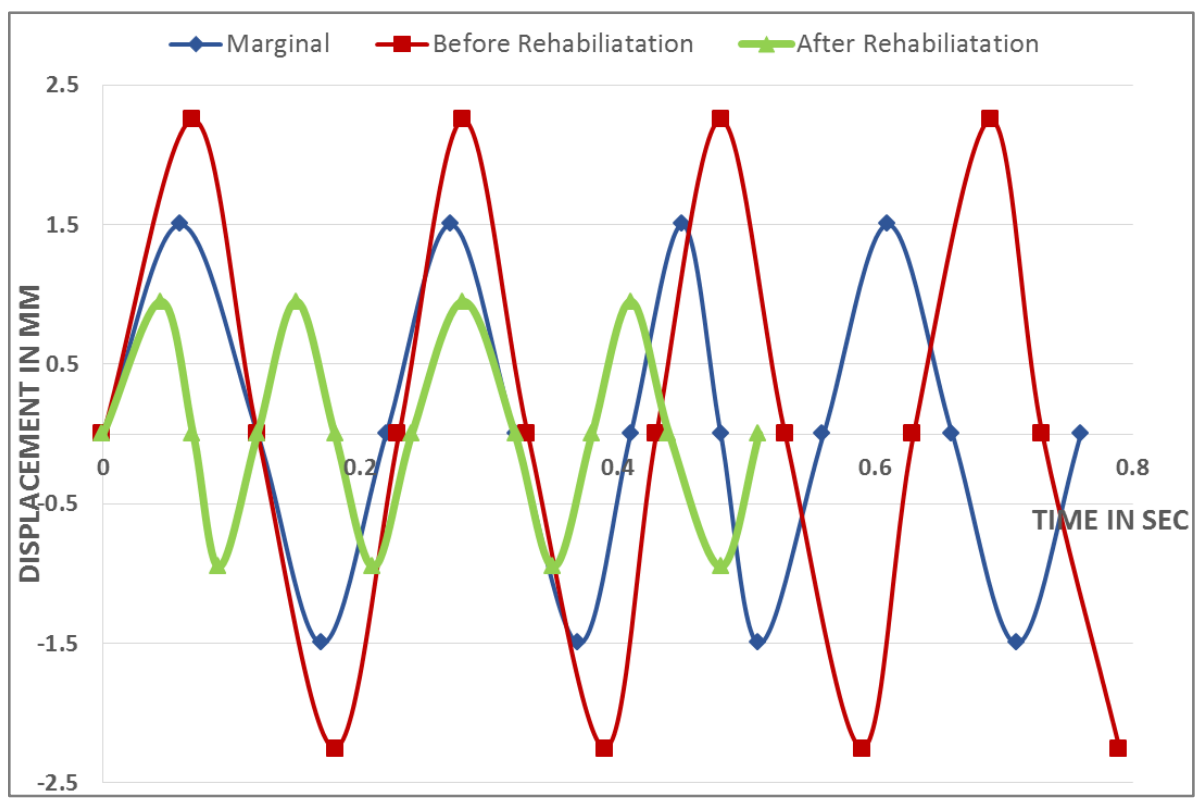

Figure 14. Shows the displacement of the model before and after rehabilitation

\section{Validation of the Model}

The validity of the model developed in this paper is explained with examples with an increase in the load carrying capacity of the beam and the mode of repair for the damaged beam. The design parameter of the damaged beam is found to be crack opening $\left(\mathrm{C}_{\mathrm{o}}\right)$ is 0.001 , ratio of the width of the crack to the width of the opening $\left(\mathrm{W}_{\mathrm{c}} / \mathrm{W}_{\mathrm{b}}\right)$ is 0.3 , load $=80 \mathrm{~N}$, Damage $=0.82$. Using table 2 , it is noted that the beam needs to be rehabilitated with a composite whose modulus of elasticity is two times the modulus of elasticity of the concrete and is applied throughout the damaged section of the beam. The displacement of the model is studied before and after rehabilitation and is shown in figure 14. From the result, it is very clear that the displacement is reduced considerably after rehabilitation. In this example, it is tried with a composite whose modulus of elasticity is 1.2 and 1.5 times the modulus of concrete and is found that it is not effective in reducing the displacement. 


\section{Conclusions}

An attempt is made in the paper to design a composite for rehabilitation of damaged beams based on stiffness and displacement. To achieve the above objective, analysis is carried out using ANSYS 10 for various cases by considering the width of the crack/width of the beam ratio, Young's modulus, opening of the crack as variables. Percentage increase in stiffness and percentage reduction in displacement for undamaged, damaged and composite models are determined and equations have been developed which enable people to design the composite for repair and rehabilitation of damaged beam. It is found that the influence of crack opening is not making any changes while finding the composite for repair provided if the width of the crack is comparatively higher than opening of the crack.

\section{REFERENCES}

[1] Bazant, Z.P, Concrete fracture models: testing and practice, Engineering Fracture Mechanics, Vol.69, No.2, pp.165-205, 2002.

[2] Shekarbeigi, $M$ and Sharafi $\mathrm{H}$, Analysis of concrete materials models, Special issue of current world Environment, Vol.10, 2015.

[3] Kong, Y, Bennette, C.J, and Hyde C.J, A review of non-destructive testing techniques for the in-situ investigation of fretting fatigue cracks, Materials and Design, Vol.196, pp.1-27, 2020.

[4] Meola, C Recent Advances in Non- destructive testing, Nova Publishers, New York, 2010

[5] Hillerborg, A, A Model for Fracture Analysis, (Report TVBM-3005), Division of Building Materials, Lund University, Sweden, 1978.

[6] Bazant, Z.P and Planas, J, Fracture and Size Effect in concrete and other Quasi-brittle materials, Routledge, New York, 2019. https://doi.org/10.1201/9780203756799

[7] Jenq, Y.S and Shah S.P, A two parameter fracture model for concrete, Journal of Engineering Mechanics, Vol.3, No.4, pp.1227-1241, 1985.

[8] Ince, R and Alyamac, K. E, Determination of fracture parameters of concrete based on water cement ratio, Indian Journal of Engineering and material science, Vol.15, pp.14-22, 2008.

[9] Lau, K.T and Zhou, L.M, Mechanical performance of composite-strengthened concrete structures, Journal of Composites, Vol.32, No.1, pp.21-31, 2001.

[10] Alexander Newman, P.E., Structural Renovation of Buildings: Methods, Details and Design Examples, McGraw-Hill, New York, 2001.

[11] Restuccia, L, Reggio, A, Ferro, G.A, and Tulliani, J.M, New self-healing techniques for cement-based materials, Procedia Structural Integrity, Vol. 3, pp. 253-260, 2017.

[12] Khattab, I.M.A, Shekha, H, and Abdi, M.A, Study on Self-healing Concrete types - A review, Sustainable Structure and Materials, Vol. 2, No.1, pp.76-87, 2019. https://doi.org/10.26392/SSM.2019.02.01.076

[13] Danish, A, Mosaberpanah, M.A, and Salim, M.U, Past and present techniques of self-healing in cementitious materials: A critical review on efficiency of implemented treatments, Journal of Materials Research and Technology, Vol 9, No.3, pp. 6883-6899, 2020.

[14] Yan, A Ke-Ru Wu, Dong Zhang and Wu Yao, Influence of concrete composition on the characterization of fracture surface, Cement and Concrete Composites, Vol. 25, No.1, 153-157, 2003.

[15] ANSYS, Academic Research Structures, Release 12, Structures Guide, ANSYS, Inc., 2009.

[16] International Building code -IBC International Code Council, Inc., 2018.

[17] Shifana, F.S, Natarajan, C, and Shamim S.K, Strength assessment and rehabilitation of damaged beam using fuzzy information, International Journal of Earth Sciences and Engineering. Vol.12, No.3, pp. 143-148, 2019. 